\title{
Consumption of Ultra-processed Foods and Obesity in Brazilian Adolescents and Adults
}

Running title: Ultra-processed Foods and Obesity

Maria Laura da Costa Louzada ${ }^{1,2}$, Larissa Galastri Baraldi ${ }^{1,2}$, Euridice Martinez Steele $^{1,2}$, Ana Paula Bortoletto Martins ${ }^{2}$, Daniela Silva Canella ${ }^{2}$, Jean ClaudeMoubarac $^{2}$, Renata Bertazzi Levy ${ }^{2,3}$, Geoffrey Cannon ${ }^{2}$, Ashkan Afshin ${ }^{4}$, Fumiaki Imamura $^{5}$, Dariush Mozaffarian ${ }^{4}$, Carlos Augusto Monteiro ${ }^{1,2}$.

${ }^{1}$ Departamento de Nutrição, Faculdade de Saúde Pública, Universidade de São Paulo, Av. Dr. Arnaldo, 715, $2^{\circ}$ floor - São Paulo 01246-907, Brazil.

${ }^{2}$ Núcleo de Pesquisas Epidemiológicas em Nutrição e Saúde, Universidade de São Paulo, Av. Dr. Arnaldo, 715, S27 - São Paulo 01246-907, Brazil. ${ }^{3}$ Departamento de Medicina Preventiva, Faculdade de Medicina, Universidade de São Paulo, Av. Dr. Arnaldo, 455, S27 - São Paulo 01246-903, Brazil.

${ }^{4}$ Friedman School of Nutrition Science \& Policy, Tufts University, 150 Harrison Ave, Boston, MA 02111, United States.

${ }^{5}$ Medical Research Council Epidemiology Unit, Institute of Metabolic Science, University of Cambridge, School of Clinical Medicine, Cambridge Biomedical Campus, Hills Road, Cambridge CB2 OSP, Cambridge, UK.

Emails:

Maria Laura da Costa Louzada - maria.laura.louzada@ gmail.com

Ana Paula Bortoletto Martins - anapbmartins@ gmail.com

Daniela Silva Canella - danicanella@gmail.com

Larissa Galastri Baraldi - laribaraldi@gmail.com

Renata Bertazzi Levy-rlevy@usp.br

Jean-Claude Moubarac - jcmoubarac@gmail.com

Geoffrey Cannon - geoffreycannon@aol.com 
Carlos Augusto Monteiro - carlosam@usp.br

Euridice Martinez Steele - emar_steele@hotmail.com

Ashkan Afshin - ashkan.Afshin@tufts.edu

Fumiaki Imamura - fumiaki.imamura@mrc-epid.cam.ac.uk

Dariush Mozaffarian - dariush.mozaffarian@tufts.edu

Correspondence: Maria Laura da Costa Louzada, Departamento de Nutrição, Faculdade de Saúde Pública, Universidade de São Paulo, Av.

Dr. Arnaldo, 715, São Paulo 01246-907, Brazil. Phone number: +55 11

30617854 E-mail: maria.laura.louzada@gmail.com

Word counts:

Main text - 2,500

Abstract - 199

M.L.C. Louzada was funded by the São Paulo Research Foundation $(2013 / 08260-1)$

J-C. Moubarac was funded by the São Paulo Research Foundation (2011/084255)

F. Imamura was supported by Medical Research Council Epidemiology Unit Core Support (MC_UU_12015/5).

D. Mozaffarian declare: Ad hoc honoraria for one-time scientific presentations/reviews on diet from Quaker Oats, Pollock Institute, and Bunge (each <10k/12 months); ad hoc consulting for Foodminds, Nutrition Impact, Amarin, Astra Zeneca, Winston and Strawn LLP, and Life Sciences Research 
Organization (each <10k/12 months); Unilever North America Scientific Advisory Board (<10k/12 months), royalties from UpToDate, for an online chapter on fish oil (<10k/12 months). 


\begin{abstract}
Objectives: to evaluate the relationship between the consumption of ultraprocessed foods and obesity indicators among Brazilian adults and adolescents. Methods: We used cross-sectional data on 30,243 individuals aged $\geq 10$ years from the 2008-2009 Brazilian Dietary Survey. Food consumption data were collected through 24-hour food records. We classified food items according to characteristics of food processing. Ultra-processed foods were defined as formulations made by the food industry mostly from substances extracted from foods or obtained with the further processing of constituents of foods or through chemical synthesis, with little if any whole food. Examples included candies, cookies, sugar-sweetened beverages, and ready-to-eat dishes. Regression models were fitted to evaluate the association of the consumption of ultra-processed foods (\% of energy intake) with body-mass-index, excess weight, and obesity status, controlling for socio-demographic characteristics, smoking, and physical activity.
\end{abstract}

Results: Ultra-processed foods represented $30 \%$ of the total energy intake. Those in the highest quintile of consumption of ultra-processed foods had significantly higher body-mass-index $\left(0.94 \mathrm{~kg} / \mathrm{m}^{2} ; 95 \% \mathrm{CI}: 0.42,1.47\right)$ and higher odds of being obese $(\mathrm{OR}=1.98$; 95\%CI: 1.26,3.12) and excess weight $(\mathrm{OR}=1.26$; 95\%CI: $0.95,1.69)$ compared with those in the lowest quintile of consumption.

Conclusion: Our findings support the role of ultra-processed foods in the obesity epidemic in Brazil.

Key-words: Food; Nutrition; Risk factor; Obesity; Prevention 


\section{INTRODUCTION}

Ultra-processed foods are formulations made by the food industry mostly from substances extracted from foods or obtained from the further processing of constituents of foods or through chemical synthesis, with little if any whole foods (Monteiro et al., 2012; Moodie et al., 2013). Compared to the rest of the diet, these formulations have less fiber and protein, more added sugar, and, when solid, higher energy density (Monteiro et al., 2011; Moubarac et al., 2012). They are also extremely palatable and habit-forming, convenient, sold in large portion sizes, and aggressively advertised and marketed (Monteiro et al., 2012; Moodie et al., 2013; Ludwig, 2011). Sales of ultra-processed foods have increased in parallel with the rates of obesity worldwide, particularly in middleincome countries (Monteiro et al., 2013).

One analysis in Brazil showed that household purchase of ultra-processed foods was associated with greater prevalence of obesity (Canella et al., 2014). However, this study had only used purchase data rather than individual-level consumption data. To our knowledge, no evidence in a developing country is available for how much people consume ultra-processed foods across different demographic groups and how it is related to obesity.

The objective of the present study was to evaluate the association of the intake of ultra-processed foods with obesity indicators in a nationally representative sample of Brazilian adolescents and adults. 


\section{METHODS}

\section{Design and population}

We performed a cross-sectional analysis based on individual-level dietary data from 34,003 individuals aged $\geq 10$ years in Brazil, collected as part of the 20082009 National Household Budget Survey (Ibge, 2011a). These individuals represented a randomly selected subsample of $25 \%$ of the 55,970 total households randomly selected for the budget survey. The survey employed a complex clustered sampling procedure, first selecting census tracts and then selecting households within those tracts. The selection of census tracts was preceded by an examination of the tracts of the Master Sample of Household Surveys or Common Sample (containing the pool of the 12,800 tracts of the country) to obtain strata of households with high geographic and socioeconomic homogeneity. The geographic locations of tracts (region, state, capital city or other, urban or rural) and the years of schooling of the heads of households in the sector were considered, and 550 strata of households that were geographically and socioeconomically homogeneous were selected. For this study, we excluded pregnant women and individuals with diabetes, hypertension or cancer, each defined by self-reported medication $(n=3,760)$.

The project was approved by the Ethics Committee of the University of São Paulo.

\section{Food consumption}

Individuals completed two non-consecutive 24-hour food records days spanning one week (Ibge, 2011a). Nutrient intakes were estimated based on a Brazilian food composition table (Ibge, 2011b). 
Food items were divided into three main groups (Supplementary Figure 1). The first was composed of unprocessed, minimally, or moderately processed foods. Unprocessed foods were defined as having not undergone any kind of industrial processing, minimally processed foods as processed in ways that did not add substances or subtract edible parts, and moderately processed foods as those that had an edible part subtracted, but no substance added. This category also included handmade dishes made from these foods and culinary ingredients such as oils, salt, and sugar. The second category was processed foods, and the third, ultra-processed foods. Processed and ultra-processed foods were defined as products made by the food industry with at least two ingredients. We characterized processed foods as those manufactured by adding salt, sugar, or oil to unprocessed, minimally processed or moderately processed foods; and ultraprocessed foods as those formulations mostly made from substances extracted from foods or obtained with the further processing of constituents of foods or through chemical synthesis, such as oils, hydrogenated fats, starches, sugars, protein isolates, amino acids, and additives like flavors and colors (Monteiro et al., 2012; Moodie et al., 2013; Ludwig, 2011; Monteiro and Cannon, 2012). Examples of ultra-processed foods include: ice-creams, soft drinks, industrialized baked products, and sausages.

For each category, we computed the relative contribution of foods in that category to each person's total energy intake. We evaluated intake as the percentage to total energy intake in order to reduce variation due to body size, physical activity, and metabolic efficiency (each major determinants of total energy intake).

\section{Obesity indicators}

Weight and height were measured by researchers with standard techniques and recorded in specific questionnaires (Ibge, 2011a). In individuals aged $\geq 20$ years 
old, excess weight and obesity were defined as BMI $\geq 25 \mathrm{~kg} / \mathrm{m}^{2}$ and $30 \mathrm{~kg} / \mathrm{m}^{2}$, respectively (WHO, 1995). Excess weight and obesity of 10 to 19 year-old individuals were defined as BMI-for-age z-scores from the World Health Organization references $\geq+1$ and +2 , respectively (de Onis et al., 2007). Excess weight includes excess weight and obesity.

\section{Covariates}

Information on age, sex, race, education, and income were obtained via standardized interviews. Annual household income per person was calculated using a purchasing power parity basis (PPP 2009: US\$ 1.00=R $\$ 1.63$ ) (World Bank, 2015). Geographic region and urban status of the household were also used as covariates.

Smoking was assessed based on data from each individual's purchases, with current smokers defined as those having purchased any type of cigarettes during the previous 7 days. Because physical activity was not assessed in the household survey, we predicted physical activity levels by evaluating data from the VIGITEL Survey (Ministério da Saúde, 2010) for adults and from the PENSE Survey (Ministério da Saúde, 2009) for adolescents. Using these datasets, we modeled a regression equation predicting the likely leisure-time and transportation physical activity (minutes/week) by age, sex, race, years of education, and smoking status used as the predictors. Using two regression equations, we obtained predicted leisure-time and transportation physical activity duration for individuals in the dataset of the current study.

Statistical analyses 
Analyses were performed with Stata 13.0 (Texas, US) with two-tailed alpha $=0.05$. Analyses accounted for sample weights and the design effect of the survey.

Linear regression models were used to assess differences in BMI across quintiles of consumption of ultra-processed foods (\% of total energy).

Logistic regression models were fitted in order to evaluate the odds ratio (OR) for being excess weight or obese according to quintiles of consumption of ultraprocessed foods (\% of total energy).

Multivariate models were fitted to adjust for age, sex, race, region, urban status, education, income, smoking status, and physical activity levels. We further adjusted for each person's consumption of fruits, vegetables, and beans to evaluate if the association was independent of these other components of the diet. Total energy intake was not included as a covariate because it may plausibility mediate (i.e., be in the causal pathway of) the effects of ultraprocessed foods on BMI and obesity. We performed sensitivity analyses using the energy intake of ultra-processed foods (and not the percentage of total energy intake of the diet) as the explanatory variable.

We explored potential effect modification by sex, age, household income and food consumption outside home. For any significant interactions, subgroup analyses were conducted.

Lastly, we examined whether the association remained significant after adjustment, one at a time, for dietary intakes of saturated fatty acids (g/day), trans fatty acids (g/day), added sugars (\% of total energy), fiber (g/1,000 kcal), and total energy ( $\mathrm{kcal} / \mathrm{day})$. We calculated the percent change in the regression coefficient for a linear relationship of the association between the consumption 
of ultra-processed foods and BMI before and after adjustment for each of the selected factors, by using an ordinal variable for quintile categories of consumption of ultra-processed foods (\% of total energy).

\section{RESULTS}

A total of 30,243 Brazilian adults were evaluated (Table 1). Consistent with the national population, the great majority resided in urban areas, $51 \%$ were women and 52\% African-descendent. Forty-one percent of the participants were excess weight and $12 \%$ obese.

Mean reported energy intake was $1,908 \mathrm{kcal}$. Nationally, more than two thirds $(68.6 \%)$ of these calories came from unprocessed, minimally, or moderately processed foods, while $29.6 \%$ came from ultra-processed foods.

On average, rice and beans represented about $25 \%$ of the energy consumed throughout the day (Supplementary Table 1). Other major foods in the Brazilian diet were red meat $(9.3 \%$ of total energy), fruits $(6.9 \%)$ and cereals other than rice $(5.9 \%)$. Among ultra-processed foods, the categories with the highest energy contribution were industrialized breads (9.2\% of total energy intake), pizzas, hamburgers and sandwiches (4.7\%), and cakes and cookies (3.0\%).

The consumption of ultra-processed foods ranged from an average of $6.0 \%$ of total energy intake in the lowest quintile to $56.0 \%$ in the highest quintile of consumption of ultra-processed foods (\% of total energy). In crude (unadjusted) analyses, the percent energy from ultra-processed foods was higher among woman, those with urban residency, non-smokers, and those with higher levels of physical activity, education, and income (Supplementary Table 2). Total energy intake ranged from $1,784 \mathrm{kcal}$ in the bottom quintile to 2,060 kcal in the top quintile of ultra-processed foods. 


\section{Ultra-processed foods and obesity}

After adjustment for sociodemographics, smoking, and physical activity, the consumption of ultra-processed foods was associated with higher BMI and greater prevalence of both excess weight and obesity (Table 2). Compared to those in the first quintile of consumption of ultra-processed foods, mean BMI was $0.94 \mathrm{~kg} / \mathrm{m}^{2}$ higher among those in the top quintile $(95 \% \mathrm{CI}=0.42,1.47)$. The adjusted odds ratio (OR) of being obese or excess weight were, respectively, $1.98(95 \% \mathrm{CI}=1.23,3.12)$ and $1.26(95 \% \mathrm{CI}=0.95,1.69)$ in the top quintile of ultra-processed foods intake. Further adjustment for consumption of fruits, vegetables, and beans had little effect on these risk estimates (Table 2).

\section{Analysis of interaction}

We observed a significant effect modification in the relationship between consumption of ultra-processed foods and BMI by both age and sex $(P<0.001$ each), but neither by income nor by food consumption outside home $(P>0.05)$. No effect modification in the relationship between the consumption of ultraprocessed foods and obesity was observed $(P>0.05)$. Subgroup analyses showed that the trend toward positive associations for both BMI and obesity remained in all age groups (Table 3).

A strong association between the consumption of ultra-processed foods and both BMI, excess weight and obesity was observed among women, but not among men (Table 4). The mean difference in BMI was $1.13 \mathrm{~kg} / \mathrm{m}^{2}$ comparing women in the top to the bottom quintile groups of ultra-processed food consumption $(95 \% \mathrm{CI}=0.38,1.87)$. The OR of being obese was 1.96 in women with the highest consumption of ultra-processed foods $(95 \% \mathrm{CI}=1.09,3.56)$. 


\section{Additional analyses}

Additional adjustment for saturated fat, trans fat, and added sugar had little effect on the magnitude of the associations. For example, after adjustment for fiber, the association of consuming ultra-processed foods with BMI was attenuated by only 7\%, Adjustment for total energy intake, a key potential mediator of the association, attenuated the association with BMI by $50 \%$, although the association remained statistically significant $(P=0.001)$. The adjustment for total energy reduced the magnitude of the linear relationship from $0.22 \mathrm{~kg} / \mathrm{m}^{2}(95 \% \mathrm{CI}=0.12$ to 0.32$)$ to $0.10 \mathrm{~kg} / \mathrm{m}^{2}(0.04,0.17)$ per quintile category of ultra-processed foods.

The results were similar when we evaluated the quintiles of energy intake of ultra-processed foods rather than the percentage of total energy intake of the diet as the explanatory variable (data not shown). Compared to those in the bottom group, adjusted mean BMI was $0.78 \mathrm{~kg} / \mathrm{m}^{2}$ higher among those in the last quintile group $(95 \% \mathrm{CI}=0.0 .49,1.08 ; P$ for trend=0.001). The adjusted $\mathrm{OR}$ of being obese and excess weight were, respectively, 1.53 (95\% CI=1.21,1.94; ; $P$ for trend=0.001) and $1.33(95 \% \mathrm{CI}=1.13,1.57 ; P$ for trend $=0.01)$.

\section{DISCUSSION}

We found a cross-sectional association between the intake of ultra-processed foods and excess weight and obesity among Brazilian adolescents and adults. Although there was heterogeneity by sex and age, our finding supports that, on average, there are potential detrimental effects of consuming ultra-processed foods.

We suggest that this association is, at least partially, explained by intrinsic characteristics of ultra-processed foods that promote overconsumption. This is 
particularly important when we attempt to the fact that the consumption of these foods has widely increased worldwide, in parallel with the global increase in obesity (Monteiro et al., 2013; Finucane et al., 2011; Martins et al., 2013).

Our study showed that almost one third of the energy consumed in Brazil came from ultra-processed foods. This may partly related to their convenience, portability, and perceived time-saving compared with less processed foods. Typically, ultra-processed foods are designed to be consumed anywhere and often, without implements. These foods are usually sold in the form of snacks, drinks, or ready-to-consume dishes and can readily displace handmade meals. Also, the processing techniques and the cosmetic additives make ultra-processed foods hyper-palatable. They are therefore liable to cause "mindless eating" and to damage the processes that control satiety and appetite (Ludwig, 2011; Ogden et al., 2013). SSBs are a particular case. Their consumption can lead to weight gain by an incomplete compensatory reduction in energy intake at subsequent meals following intake of liquids (Dimeglio and Mattes, 2000). Another possible link between the consumption of ultra-processed foods with obesity is the portion size. Portion sizes of many ultra-processed foods significantly increased in past decades (Piernas and Popkin, 2001; Nielsen and Popkin, 2003) and several studies have linked their increases to increased total energy intake (Albar et al., 2014; Steenhuis and Vermeer, 2009; Diliberti et al., 2004) All these characteristics are amplified by aggressive marketing, which makes these products attractive and ubiquitous, and modifies social norms (Mallarino et al., 2013).

Due to the lack of water and the type of carbohydrates, ultra-processed foods have high glycemic loads and, when solid, high energy density (Monteiro et al., 2011; Ludwig, 2011). This is particularly relevant since individuals regulate food consumption by volume more so than calories and energy density is inversely related to diet quality and directly associated to energy intake (Rolls, 
2009). Likewise, high glycemic loads can cause an increased insulin response, which might promote weight gain by directing nutrients away from oxidation in muscle and towards storage in fat (Ludwig, 2002; Brand-Miller et al., 2009).

Ultra-processed foods are nutritionally unbalanced (Monteiro et al., 2011; Moubarac et al., 2012); they have poor quality fat and low contents of fiber, micronutrients, and phytochemicals. Still, we couldn't show a significant importance of the contents of saturated fat, trans fat, added sugar, and fiber to explain the results. Nevertheless, food composition table can have imprecise information, biasing the results to null. Further studies, thus, should explore the impact of the consumption of ultra-processed foods and the effects of their entire nutrient profile on health outcomes.

We observed a strong effect modification related to sex. We hypothesized that unmeasured confounders or confounders measured with error may partly explain the absence of effect among men. Previous Brazilian studies described higher levels of physical activity and smoking among men (Malta et al., 2011). Since it is well established that both characteristics are inversely correlated to BMI, the lack of an appropriate control may be biasing the results to null. Growing evidence suggests that women are more predisposed to adverse metabolic effects of rapidly digested, carbohydrate-rich foods than men, which might explain larger effects of ultra-processed foods on adiposity in women (Mirrahimi et al, 2014). Different stress coping mechanisms between both sexes could also be considered as a possible cause of the different findings between men and women. For instance, perceived stress has been an important predictor of both diet quality and adiposity, and women are particularly susceptible to perceived stress (de Vriendt et al., 2012; Isasi et al., 2015; Nastaskin et al., 2015). In addition, a population-based study showed different socioeconomic determination of obesity in men and women, increasing the complexity of modeling these variables (Monteiro et al., 2001). Our study brings novel 
evidence on sex-specific associations even though the reasons behind these results remain unknown and should be further explored.

On the other hand, other subgroup analyses confirmed that the association is consistent across age, socioeconomic status groups, and different patterns of outside home consumption, increasing the confidence in the results.

Our findings are consistent with studies from high-income countries that have assessed the influence on obesity of foods that could be classified as ultraprocessed. In the US, positive associations have been seen between consumption of potato chips, SSBs, and processed meat and long-term weight gain; with protective associations of unprocessed or minimally processed foods such as fruits, vegetables, nuts, and yogurt (Mozaffarian et al., 2011). Also, a 15-year prospective study showed that fast food consumption among young adults was directly associated with changes in body weight and insulin resistance (Pereira et al., 2005). Regarding SSBs, strong epidemiological evidence describes their role in the etiology of obesity and other cardiovascular diseases (Woodwardlopez et al., 2010; HU and Malik, 2010).

Our study has several strengths. We analyzed contemporary data on more than 30,000 people on the first nationally representative individual dietary survey from Brazil. Availability of socioeconomic and demographic variables allowed adjustment for many important covariates, as well as evaluation of consistency among population subgroups. We believe that the food classification used in this study is advantageous compared to previous classifications. In prior studies, foods were usually grouped according to their nutrient profile. For example, unprocessed and processed meats were frequently classified in the same category because of their protein content, and grains and flour-based products were grouped together because they are both sources of carbohydrates (Monteiro et al., 2012). These classifications could be important when most of 
the nutrition-related diseases were caused by deficiencies of nutrients (Monteiro et al., 2012). However, the classifications based solely on nutrient composition have been shown to be unable to explain the entire influence of food consumption on obesity. We strongly believe that considering industrial food processing in the assessment of food consumption can bring novel evidence for the elucidation of the framework of the obesity epidemic.

There are several limitations to the interpretation of our findings as well. First, this study is cross-sectional. Our results are susceptible to reverse causation and provide little causal information. Although we attempted to control for potential confounders for the association between the consumption of ultra-processed foods and obesity, residual confounding could remain because of unmeasured confounders and inaccuracy in measurement of smoking and physical activity. Smoking was assessed based on purchase of cigarettes, which may have underestimated smoking exposure, particularly in adolescents. Physical activity was also estimated indirectly by using a predictive model based on socioeconomic characteristics. Since it is well established that both smoking and physical activity are inversely correlated to BMI, the lack of an appropriate control may be biasing the results to null.

Despite this, effect sizes were large and the results are biologically plausible and consistent with the previous literature. Also, the study might have some bias related to inherent limitations of food records. To minimize these problems, food records were evaluated against gold standard methods, the questionnaire was validated, and quality control procedures were carried out (Ibge, 2011a). The dietary survey was not designed specifically to classify foods according to characteristics of industrial processing, which would further increase misclassification and limit ability to detect associations. 


\section{CONCLUSION}

In conclusion, our findings support the role of ultra-processed foods consumption in the obesity epidemic in Brazil. In conclusion, our findings support the role of ultra-processed foods in obesity epidemic in Brazil. While cross-sectional, the size and generalizability of our study provides evidence that may support the role of ultra-processed foods in the obesity epidemic. These results demonstrate a need for interventional studies, including policy interventions, to test the effects of reducing ultra-processed foods on obesity.

Supplementary information is available at Preventive Medicine's website 


\section{REFERENCES}

Albar SA, Alwan NA, Evans CE, Cade JE. Is there an association between food portion size and BMI among British adolescents? Br J Nutr. 2014;112(5):841-51.

Brand-Miller J, McMillan-Price J, Steinbeck K, Caterson I. Dietary glycemic index: health implications. J Am Coll Nutr. 2009;28 Suppl:446S-449S.

Brasil. Instituto Brasileiro de Geografia e Estatística (Ibge). Análise do consumo alimentar pessoal no Brasil. Instituto Brasileiro de Geografia e Estatística: Rio de Janeiro, Brazil, 2011.

Brasil. Instituto Brasileiro de Geografia e Estatística (Ibge). Antropometria e estado nutricional de crianças, adolescentes e adultos no Brasil. Instituto Brasileiro de Geografia e Estatística: Rio de Janeiro, Brazil, 2010.

Brasil. Instituto Brasileiro de Geografia e Estatística (Ibge). Tabelas de Composição Nutricional dos Alimentos Consumidos no Brasil. Instituto Brasileiro de Geografia e Estatística: Rio de Janeiro, Brazil, 2011.

Brasil. Ministério da Saúde. Pesquisa Nacional de Saúde do Escolar 2009. Brasília: Ministério da Saúde, Ministério da Saúde: Brasília, Brazil, 2009.

Brasil. Ministério da Saúde. Vigitel Brasil 2009: vigilância de fatores de risco e proteção para doenças crônicas por inquérito telefônico. Ministério da Saúde: Brasília, Brazil, 2010.

Canella DS, Levy RB, Martins AP, Claro RM, Moubarac JC, Baraldi LG, et al. Ultraprocessed food products and obesity in Brazilian households (2008-2009). PLoS One. 2014;9(3):e92752.

de Onis M, Onyango AW, Borghi E, Siyam A, Nishida C, Siekmann J. Development of a WHO growth reference for school-aged children and adolescents. Bull World Health Organ. 2007;85(9):660-667.

de Vriendt T, Clays E, Maes L et al. European adolescents' level of perceived stress and its relationship with body adiposity--the HELENA Study. Eur J Public Health 2012;22(4):519-524.

Diliberti N, Bordi PL, Conklin MT, Roe LS, Rolls BJ. Increased portion size leads to increased energy intake in a restaurant meal. Obes Res. 2004;12(3):562-568.

DiMeglio DP, Mattes RD. Liquid versus solid carbohydrate: effects on food intake and body weight. Int J Obes Relat Metab Disord. 2000;24(6):794-800.

Finucane MM, Stevens GA, Cowan MJ, Danaei G, Lin JK, Paciorek CJ, et al. National, regional, and global trends in body-mass index since 1980: systematic analysis of health examination surveys and epidemiological studies with 960 country-years and 9.1

million participants. Lancet. 2011;377(9765):557-567.

Hu FB, Malik VS. Sugar-sweetened beverages and risk of obesity and type 2 diabetes: epidemiologic evidence. Physiol Behav. 2010;100(1):47-54

Isasi CR, Parrinello CM, Jung MM et al. Psychosocial stress is associated with obesity and diet quality in Hispanic/Latino adults. Ann Epidemiol 2015;25(2): 84-89.

Ludwig DS. Technology, diet, and the burden of chronic disease. JAMA.

2011;305(13):1352-1353.

Ludwig DS. The glycemic index: physiological mechanisms relating to obesity, diabetes, and cardiovascular disease. JAMA. 2002;287(18):2414-2423. Mallarino C, Gomez LF, Gonzalez-Zapata L, Cadena Y, Parra DC. Advertising of ultraprocessed foods and beverages: children as a vulnerable population. Rev Saude Publica. 2013;47(5):1006-1010.

Malta DC, Moura EC, de Morais Neto OL. Gender and schooling inequalities in risk and protective factors for chronic diseases among Brazilian adults, through telephone survey. Rev Bras Epidemiol. 2011;14 (Suppl 1):125-135. 
Martins AP, Levy RB, Claro RM, Moubarac JC, Monteiro CA. Increased contribution of ultra-processed food products in the Brazilian diet (1987-2009). Rev Saude Publica. 2013;47(4):656-665.

Mirrahimi A1, Chiavaroli L, Srichaikul K, Augustin LS, Sievenpiper JL, Kendall CW, et al. The role of glycemic index and glycemic load in cardiovascular disease and its risk factors: a review of the recent literature. Curr Atheroscler Rep. 2014;16(1):381.

Monteiro CA, Cannon G, Levy RB, Claro RM, Moubarac J-C. The Food System. Ultraprocessing. The big issue for nutrition, disease, health, well-being. [Commentary]. World Nutrition. 2012;3(12):527-569.

Monteiro CA, Cannon G. The impact of transnational "Big Food" companies on the south: a view from Brazil. Plos Med. 2012;9(7): e1001252.

Monteiro CA, Conde WL, Popkin BM. Independent effects of income and education on the risk of obesity in the Brazilian adult population. J Nutr. 2001;131(3):881-886.

Monteiro CA, Levy RB, Claro RM, de Castro IR, Cannon G. Increasing consumption of ultra-processed foods and likely impact on human health: evidence from Brazil. Public Health Nutr. 2011;14(1):5-13.

Monteiro CA, Moubarac JC, Cannon G, Ng SW, Popkin B. Ultra-processed products are becoming dominant in the global food system. Obes Rev. 2013;14 (Suppl 2):21-28.

Moodie R, Stuckler D, Monteiro C, Sheron N, Neal B, Thamarangsi T, et al. Profits and pandemics: prevention of harmful effects of tobacco, alcohol, and ultra-processed food and drink industries. Lancet. 2013;381(9867):670-679.

Moubarac JC, Martins AP, Claro RM, Levy RB, Cannon G, Monteiro CA.

Consumption of ultra-processed foods and likely impact on human health: evidence from Canada. Public Health Nutr. 2013;16(12): 2240-8.

Mozaffarian D, Hao T, Rimm EB, Willett WC, Hu FB. Changes in diet and lifestyle and long-term weight gain in women and men. N Engl J Med. 2011;364(25):23922404.

Nastaskin RS, Fiocco AJ A survey of diet self-efficacy and food intake in students with high and low perceived stress. Nutr J 2015;14(1):42.

Nielsen SJ, Popkin BM. Patterns and trends in food portion sizes, 1977-1998. JAMA. 2003;289(4):450-453.

Ogden J, Coop N, Cousins C, Crump R, Field L, Hughes S, et al. Distraction, the desire to eat and food intake. Towards an expanded model of mindless eating. Appetite.

2013;62:119-126.

Pereira MA, Kartashov AI, Ebbeling CB, Van Horn L, Slattery ML, Jacobs DR Jr, et al. Fast-food habits, weight gain, and insulin resistance (the CARDIA study): 15-year prospective analysis. Lancet. 2005;365(9453):36-42.

Piernas C, Popkin BM. Food portion patterns and trends among U.S. children and the relationship to total eating occasion size, 1977-2006. J Nutr. 2011;141(6):1159-1164.

Rolls BJ. The relationship between dietary energy density and energy intake. Physiol Behav. 2009;97(5):609-615.

Steenhuis IH, Vermeer WM. Portion size: review and framework for interventions. Int J Behav Nutr Phys Act. 2009;6:58.

Woodward-Lopez G, Kao J, Ritchie L. To what extent have sweetened beverages

contributed to the obesity epidemic? Public Health Nutr. 2010;14(3):499-509.

World Bank. PPP conversion factor. Website.

http://data.worldbank.org/indicator/PA.NUS.PPP (accessed in April 2015).

World Health Organization. Physical status: the use and interpretation of

anthropometry. World Health Organization: Geneva, Switzland, 1995. 
Table 1. Characteristics of a nationally representative sample of 30243 adolescents and adults $(\geq 10$ years old). Brazil 2008-2009 ${ }^{\text {a }}$.

\begin{tabular}{|c|c|}
\hline \multicolumn{2}{|l|}{ Age, $\%$} \\
\hline 10 to $19 \mathrm{y}$ & 24.2 \\
\hline 20 to $39 \mathrm{y}$ & 41.3 \\
\hline 40 to $59 \mathrm{y}$ & 26.0 \\
\hline 60 y or more & 8.5 \\
\hline \multicolumn{2}{|l|}{ Sex, $\%$} \\
\hline Men & 49.8 \\
\hline Women & 50.2 \\
\hline \multicolumn{2}{|l|}{ Race, $\%$} \\
\hline White & 47.3 \\
\hline African-descendant & 51.3 \\
\hline Other & 1.4 \\
\hline \multicolumn{2}{|l|}{ Urbanity, \% } \\
\hline Rural & 16.8 \\
\hline Urban & 83.2 \\
\hline \multicolumn{2}{|l|}{ Weight status, $\%$} \\
\hline Underweight $^{\mathrm{b}}$ & 2.8 \\
\hline Normal weight ${ }^{\mathrm{c}}$ & 43.7 \\
\hline Excess weight $^{\mathrm{d}}$ & 40.9 \\
\hline Obese $^{e}$ & 11.7 \\
\hline \multicolumn{2}{|l|}{ Smoking status $\%$} \\
\hline Current smoker ${ }^{\mathrm{f}}$ & 8.2 \\
\hline \multicolumn{2}{|l|}{ Years of education, $\%$} \\
\hline$\leq 4 \mathrm{y}$ & 30.8 \\
\hline 5 to $8 y$ & 27.6 \\
\hline 9 to $12 \mathrm{y}$ & 31.1 \\
\hline$>12 y$ & 10.5 \\
\hline \multicolumn{2}{|c|}{ Annual household income per person in US $\$^{\mathrm{g}}, \%$} \\
\hline$\leq 2200(\mathrm{R} \$ 3600)$ & 31.7 \\
\hline 2201 to $4400(\mathrm{R} \$ 3600$ to 7200$)$ & 27.7 \\
\hline$>4400(\mathrm{R} \$>7200)$ & 40.6 \\
\hline \multicolumn{2}{|c|}{ Leisure-time and transportation physical activity in $\min /$ week $^{\mathrm{h},} \%$} \\
\hline$<150$ & 32.7 \\
\hline$\geq 150$ & 67.3 \\
\hline \multicolumn{2}{|l|}{ Energy intake in kcal, mean } \\
\hline Total & 1908.1 \\
\hline Inside home & 1598.7 \\
\hline Outside home & 383.8 \\
\hline
\end{tabular}

Food consumption (\% of total energy $)^{\mathrm{i}}$, mean 
${ }^{\mathrm{a}}$ All statistics accounted for sample weights from the national survey

${ }^{\mathrm{b}} \mathrm{BMI}$-for-age z-scores $<-2$ for 10 to 19 year-old individuals (de Onis et al., 2007) and BMI $<18.5 \mathrm{~kg} / \mathrm{m}^{2}$ for $\geq 20$ years old individuals (WHO, 1995).

${ }^{\mathrm{c}} \mathrm{BMI}$-for-age $\mathrm{z}$-scores $\geq-2$ and $<+1$ for 10 to 19 year-old individuals (de Onis et al., 2007) and BMI $\geq 18.5 \mathrm{~kg} / \mathrm{m}^{2}$ and $<25 \mathrm{~kg} / \mathrm{m}^{2}$ for $\geq$ 20 years old individuals (WHO, 1995).

${ }^{\mathrm{d}}$ BMI-for-age $\mathrm{z}$-scores $\geq+1$ for 10 to 19 year-old individuals (de Onis et al., 2007) and BMI $\geq 25 \mathrm{~kg} / \mathrm{m}^{2}$ for $\geq 20$ years old individuals (WHO, 1995)

${ }^{\text {e}} \mathrm{BMI}$-for-age $\mathrm{z}$-scores $\geq+2$ for 10 to 19 year-old individuals (de Onis et al., 2007) and BMI $\geq 30 \mathrm{~kg} / \mathrm{m}^{2}$ for $\geq 20$ years old individuals (WHO, 1995).

${ }^{\mathrm{f}}$ The number of smokers was estimated based on the number of individuals that purchased cigarettes (budget survey data). Former smoker data was not available.

${ }^{\mathrm{g}}$ Annual household income per person was calculated using a purchasing power parity basis (PPP 2009: US\$ 1.00 = RS 1.63), multiplying by 12 months, and dividing by the number of residents in the household.

${ }^{\mathrm{h}}$ Physical activity was estimated with a linear regression model fitted with original data from previous Brazilian population-based surveys with age, sex, race, years of education and smoking status as the predictors.

${ }^{i}$ Details are given in Supplementary Materials. Unprocessed foods have not undergone any kind of industrial processing, minimally processed foods were processed in ways that did not add substances or subtract edible parts, and moderately processed foods had an edible part subtracted, but no substance added. This category includes all handmade dishes made from these foods and culinary ingredients such as fats, oils, salt, and sugar. Processed foods are manufactured by adding salt, sugar, oils or fats to unprocessed, minimally processed or moderately processed foods and ultra-processed foods are formulations mostly or entirely made from substances extracted from foods, such as oils, fats, starches, sugar, and substances obtained with the further processing of constituents of foods or through chemical synthesis, such as hydrogenated fats, modified starches, and additives used to provide the products with attractive taste, flavor, color, and texture. 
Table 2. Association of the consumption of ultra-processed foods ( $\%$ of total energy) with BMI and the prevalence of obesity and excess weight among 30243 individuals aged $\geq 10$ years old ${ }^{\mathrm{a}}$. Brazil $2008-2009$.

\begin{tabular}{|c|c|c|c|c|c|c|c|c|c|c|}
\hline \multirow[b]{4}{*}{ Mean difference $(95 \% \mathrm{CI})$ in $\mathrm{BMI}, \mathrm{kg} / \mathrm{m}^{2}$} & \multicolumn{9}{|c|}{ Quintiles of consumption of ultra-processed foods (\% of total energy) } & \multirow{4}{*}{$P$ for trend } \\
\hline & \multirow{3}{*}{$\begin{array}{c}1 \\
(\leq 13 \%) \\
\end{array}$} & \multirow{2}{*}{\multicolumn{2}{|c|}{$\begin{array}{c}2 \\
\text { (14 to } 22 \%) \\
\end{array}$}} & \multirow{2}{*}{\multicolumn{2}{|c|}{$\begin{array}{c}3 \\
\text { (23 to } 31 \%) \\
\end{array}$}} & \multirow{2}{*}{\multicolumn{2}{|c|}{$\begin{array}{c}4 \\
\text { (32 to } 43 \%) \\
\end{array}$}} & \multirow{2}{*}{\multicolumn{2}{|c|}{$\begin{array}{c}5 \\
(\geq 44 \%) \\
\end{array}$}} & \\
\hline & & & & & & & & & & \\
\hline & & & & & & & & & & \\
\hline Crude & 0.0 (Reference) & 0.28 & $(0.03,0.52)$ & 0.19 & $(-0.07,0.44)$ & 0.12 & $(-0.14,0.38)$ & -0.53 & $(-0.79,-0.27)$ & $<0.001$ \\
\hline Multivariate $^{\mathrm{b}}$ & 0.0 (Reference) & 0.33 & $(0.10,0.56)$ & 0.51 & $(0.25,0.76)$ & 0.69 & $(0.37,1.00)$ & 0.94 & $(0.42,1.47)$ & $<0.001$ \\
\hline Multivariate + other components of the diet ${ }^{c}$ & 0.0 (Reference) & 0.33 & $(0.10,0.56)$ & 0.51 & $(0.25,0.77)$ & 0.69 & $(0.38,1.00)$ & 0.95 & $(0.43,1.48)$ & $<0.001$ \\
\hline \multicolumn{11}{|l|}{ Odds ratio $(95 \%$ CI $)$ for being obese ${ }^{d}$} \\
\hline Crude & 1.0 (Reference) & 1.27 & $(1.08,1.50)$ & 1.27 & $(1.06,1.52)$ & 1.26 & $(1.05,1.49)$ & 1.16 & $(0.97,1.40)$ & 0.18 \\
\hline Multivariate $^{\mathrm{b}}$ & \multirow{2}{*}{$\begin{array}{l}1.0 \text { (Reference) } \\
1.0 \text { (Reference) }\end{array}$} & 1.3 & $(1.09,1.54)$ & 1.43 & $(1.17,1.76)$ & 1.58 & $(1.22,2.05)$ & 1.98 & $(1.26,3.12)$ & $<0.001$ \\
\hline Multivariate + other components of the $\operatorname{diet}^{\mathrm{c}}$ & & 1.29 & $(1.09,1.54)$ & 1.43 & $(1.16,1.75)$ & 1.57 & $(1.22,2.03)$ & 1.97 & $(1.26,3.09)$ & $<0.001$ \\
\hline \multicolumn{11}{|l|}{ Odds ratio $(95 \%$ CI $)$ for being excess weight ${ }^{e}$} \\
\hline Crude & 1.0 (Reference) & 1.1 & $(0.98,1.22)$ & 1.1 & $(0.98,1.23)$ & 1.07 & $(0.95,1.20)$ & 0.93 & $(0.82,1.05)$ & 0.2 \\
\hline Multivariate $^{\mathrm{b}}$ & 1.0 (Reference) & 1.1 & $(0.98,1.24)$ & 1.17 & $(1.02,1.35)$ & 1.21 & $(1.02,1.43)$ & 1.26 & $(0.95,1.69)$ & 0.02 \\
\hline Multivariate + other components of the diet ${ }^{\mathrm{c}}$ & 1.0 (Reference) & 1.1 & $(0.98,1.24)$ & 1.17 & $(1.02,1.35)$ & 1.21 & $(1.02,1.43)$ & 1.27 & $(0.95,1.69)$ & 0.02 \\
\hline
\end{tabular}

BMI: body mass index

CI: confidence interval

${ }^{\mathrm{a}}$ All statistics accounted for sample weights from the national survey

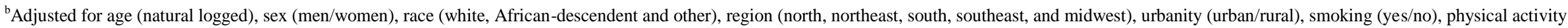
$(\mathrm{min} / \mathrm{week})$, quintiles of years of education (age- and sex-specific), per capita household income (natural logged) and the interaction between sex and income.

${ }^{\mathrm{c}}$ Covariates in the multivariate model ${ }^{\mathrm{a}}$ and consumption of fruits, vegetables and beans (each in \% of total energy intake from non-ultra-processed food)

${ }^{\mathrm{d}}$ BMI-for-age z-scores $\geq+2$ for 10 to 19 year-old individuals (de Onis et al., 2007) and BMI $\geq 30 \mathrm{~kg} / \mathrm{m}^{2}$ for $\geq 20$ years old individuals (WHO, 1995).

${ }^{\mathrm{e}}$ BMI-for-age $\mathrm{z}$-scores $\geq+1$ for 10 to 19 year-old individuals (de Onis et al., 2007) and BMI $\geq 25 \mathrm{~kg} / \mathrm{m}^{2}$ for $\geq 20$ years old individuals (WHO, 1995). 
Table 3. Association of the consumption of ultra-processed foods ( $\%$ of total energy) with BMI and the prevalence of obesity and excess weight among 30243 individuals aged $\geq 10$ years old by age groups ${ }^{\mathrm{a}}$. Brazil 2008-2009.

\begin{tabular}{|c|c|c|c|c|c|c|}
\hline & \multicolumn{5}{|c|}{ Quintiles of consumption of ultra-processed foods (\% of total energy $)^{b}$} & \multirow[b]{2}{*}{$\begin{array}{c}P \text { for } \\
\text { trend }^{\mathbf{c}}\end{array}$} \\
\hline & 1 & 2 & 3 & 4 & 5 & \\
\hline \multicolumn{7}{|l|}{ Mean difference $(95 \% \mathrm{CI})$ in BMI, $\mathrm{kg} / \mathrm{m}^{2 \mathrm{~d}}$} \\
\hline \multirow[t]{2}{*}{10 to $19 y(n=7534)^{e}$} & $\leq 17 \%$ & 18 to $28 \%$ & 29 to $39 \%$ & 40 to $52 \%$ & $\geq 52 \%$ & \\
\hline & 0.0 (Reference) & $0.01(-0.33,0.31)$ & $0.34(-0.12,0.81)$ & $0.40(-0.17,0.97)$ & $0.84(-0.16,1.85)$ & 0.08 \\
\hline \multirow{2}{*}{20 to $39 y(n=12586)$} & $\leq 13 \%$ & 14 to $23 \%$ & 24 to $32 \%$ & 32 to $44 \%$ & $\geq 45 \%$ & \\
\hline & 0.0 (Reference) & $0.02(-0.30,0.35)$ & $0.02(-0.37,0.41)$ & $0.36(-0.17,0.90)$ & $0.47(-0.42,1.36)$ & 0.15 \\
\hline \multirow[t]{2}{*}{40 to 59 y $(n=7534)$} & $\leq 11 \%$ & 12 to $19 \%$ & 20 to $28 \%$ & 29 to $38 \%$ & $\geq 39 \%$ & \\
\hline & 0.0 (Reference) & $0.58(0.09,1.07)$ & $0.51(0.02,1.00)$ & $0.70(0.10,1.31)$ & $1.12(0.25,2.00)$ & $<0.001$ \\
\hline \multirow[t]{2}{*}{60 y or more $(n=2589)$} & $\leq 10 \%$ & 11 to $18 \%$ & 19 to $25 \%$ & 26 to $36 \%$ & $\geq 37 \%$ & \\
\hline & 0.0 (Reference) & $0.21(-0.65,1.07)$ & $0.87(0.00,1.74)$ & $1.49(0.24,2.74)$ & $1.66(0.12,3.20)$ & $<0.001$ \\
\hline \multicolumn{7}{|l|}{ Odds Ratio $\left(95 \%\right.$ CI) for being obese ${ }^{\mathrm{d}, \mathrm{e}}$} \\
\hline \multirow[t]{2}{*}{10 to 19 y ( $n=7534,5 \%$ obese $)$} & $\leq 17 \%$ & 18 to $28 \%$ & 29 to $39 \%$ & 40 to $52 \%$ & $\geq 52 \%$ & \\
\hline & 1.0 (Reference) & $0.96(0.55,1.68)$ & $1.74(0.82,3.73)$ & $1.90(0.88,4.09)$ & $2.74(0.78,9.60)$ & 0.05 \\
\hline \multirow[t]{2}{*}{20 to 39 y ( $n=12586,11 \%$ obese $)$} & $\leq 13 \%$ & 14 to $23 \%$ & 24 to $32 \%$ & 32 to $44 \%$ & $\geq 45 \%$ & \\
\hline & 1.0 (Reference) & $1.27(0.96,1.68)$ & $1.31(0.95,1.79)$ & $1.48(0.99,2.20)$ & $1.53(0.76,3.06)$ & 0.08 \\
\hline \multirow[t]{2}{*}{40 to 59 y $(n=7534,18 \%$ obese $)$} & $\leq 11 \%$ & 12 to $19 \%$ & 20 to $28 \%$ & 29 to $38 \%$ & $\geq 39 \%$ & \\
\hline & 1.0 (Reference) & $1.24(0.94,1.65)$ & $1.32(0.97,1.81)$ & $1.36(0.92,2.00)$ & $1.69(0.93,3.09)$ & $<0.001$ \\
\hline \multirow[t]{2}{*}{60 y or more $(n=2589,16 \%$ obese $)$} & $\leq 10 \%$ & 11 to $18 \%$ & 19 to $25 \%$ & 26 to $36 \%$ & $\geq 37 \%$ & \\
\hline & 1.0 (Reference) & $1.65(1.14,2.38)$ & $1.74(1.14,2.67)$ & $2.07(1.24,3.45)$ & $2.62(1.22,5.64)$ & $<0.001$ \\
\hline \multicolumn{7}{|l|}{ Odds Ratio $\left(95 \%\right.$ CI) for excess weight ${ }^{\mathrm{d}, \mathrm{f}}$} \\
\hline \multirow[t]{2}{*}{10 to 19 y $(n=7534,22 \%$ excess weight $)$} & $\leq 17 \%$ & 18 to $28 \%$ & 29 to $39 \%$ & 40 to $52 \%$ & $\geq 52 \%$ & \\
\hline & 1.0 (Reference) & $1.05(0.78,1.41)$ & $1.12(0.77,1.61)$ & $1.15(0.74,1.77)$ & $1.52(0.75,3.07)$ & 0.25 \\
\hline \multirow[t]{2}{*}{20 to 39 y ( $n=12586,41 \%$ excess weight $)$} & $\leq 13 \%$ & 14 to $23 \%$ & 24 to $32 \%$ & 32 to $44 \%$ & $\geq 45 \%$ & \\
\hline & 1.0 (Reference) & $1.00(0.81,1.25)$ & $1.01(0.81,1.25)$ & $1.14(0.86,1.51)$ & $1.35(0.83,2.18)$ & 0.14 \\
\hline
\end{tabular}


40 to 59 y $(n=7534,55 \%$ excess weight $)$
$\leq 11 \%$
12 to $19 \%$
20 to $28 \%$
29 to $38 \%$
$\geq 39 \%$

1.0 (Reference)

$1.06(0.86,1.31)$

$1.10(0.88,1.38)$

$1.21(0.95,1.53)$

$1.19(0.92,1.55)$

60 y or more ( $n=2589,53 \%$ excess weight)

$$
\leq 10 \%
$$

11 to $18 \%$

19 to $25 \%$

26 to $36 \%$

$\geq 37 \%$

1.0 (Reference)

$0.87(10.59,1.28)$

$1.24(0.83,1.85)$

$1.23(0.74,2.03)$

$1.55(0.58,4.12)$

0.02

BMI: body mass index CI: confidence interval

${ }^{\text {a }}$ All statistics accounted for sample weights from the national survey

${ }^{\mathrm{b}}$ The quintiles of consumption (\% of total energy) of ultra-processed foods are specific for each subgroup

${ }^{\mathrm{c}} P$ for the interaction term on the linear regression $<0.001$

${ }^{\mathrm{d} A d j u s t e d ~ f o r ~ a g e ~(l n), ~ s e x ~(m e n / w o m e n), ~ r a c e ~(w h i t e, ~ A f r i c a n-d e s c e n d e n t ~ a n d ~ o t h e r), ~ r e g i o n ~(n o r t h, ~ n o r t h e a s t, ~ s o u t h, ~ s o u t h e a s t, ~ a n d ~ m i d w e s t), ~ u r b a n ~ s t a t u s ~(y e s / n o), ~ s m o k i n g ~(y e s / n o), ~ p h y s i c a l ~ a c t i v i t y ~}$

( $\mathrm{min} /$ week), quintiles of years of education (age- and sex-specific) per capita household income (ln), consumption of fruits, vegetables and beans (each in \% of total energy intake from non-ultra-processed

food) and the interaction between sex and income.

${ }^{\mathrm{e}} \mathrm{BMI}$-for-age z-scores $\geq+2$ for 10 to 19 year-old individuals (de Onis et al., 2007) and BMI $\geq 30 \mathrm{~kg} / \mathrm{m}^{2}$ for $\geq 20$ years old individuals (WHO, 1995).

${ }^{\mathrm{f}} \mathrm{BMI}$-for-age $\mathrm{z}$-scores $\geq+1$ for 10 to 19 year-old individuals (de Onis et al., 2007) and BMI $\geq 25 \mathrm{~kg} / \mathrm{m}^{2}$ for $\geq 20$ years old individuals (WHO, 1995). 
Table 4. Association of the consumption of ultra-processed foods (\% of total energy) with BMI and the prevalence of obesity and excess weight among 30243 individuals aged $\geq 10$ years old by sex $^{\mathrm{a}}$. Brazil 2008-2009.

\begin{tabular}{|c|c|c|c|c|c|c|}
\hline & \multicolumn{5}{|c|}{ Quintiles of consumption of ultra-processed foods $(\% \text { of total energy })^{b}$} & \multirow{3}{*}{$P$ for trend ${ }^{\mathrm{c}}$} \\
\hline & 1 & 2 & 3 & 4 & 5 & \\
\hline \multicolumn{6}{|l|}{ Mean difference $(95 \% \mathrm{CI})$ in $\mathrm{BMI}, \mathrm{kg} / \mathrm{m}^{2 \mathrm{~d}}$} & \\
\hline \multirow[t]{2}{*}{$\operatorname{Men}(n=14396)$} & $\leq 11 \%$ & 12 to $20 \%$ & 21 to $30 \%$ & 30 to $42 \%$ & $\geq 43 \%$ & \\
\hline & 0.0 (Reference) & $0.21(-0.05,0.48)$ & $0.16(-0.17,0.48)$ & $0.30(-0.10,0.71)$ & $0.32(-0.36,1.01)$ & 0.21 \\
\hline \multirow[t]{2}{*}{ Women $(n=15847)$} & $\leq 14 \%$ & 15 to $23 \%$ & 24 to $33 \%$ & 34 to $45 \%$ & $\geq 46 \%$ & \\
\hline & 0.0 (Reference) & $0.54(0.17,0.90)$ & $0.67(0.26,1.08)$ & $0.86(0.39-1.32)$ & $1.13(0.38,1.87)$ & $<0.001$ \\
\hline \multicolumn{7}{|l|}{ Odds ratio $(95 \%$ CI $)$ for being obese ${ }^{d, e}$} \\
\hline \multirow[t]{2}{*}{$\operatorname{Men}(n=14396,10 \%$ obese $)$} & $\leq 11 \%$ & 12 to $20 \%$ & 21 to $30 \%$ & 30 to $42 \%$ & $\geq 43 \%$ & \\
\hline & 1.0 (Reference) & $1.36(1.04,1.78)$ & $1.15(0.84,1.55)$ & $1.30(0.89,1.89)$ & $1.06(0.55,2.04)$ & 0.28 \\
\hline \multirow[t]{2}{*}{ Women ( $n=15847,13 \%$ obese) } & $\leq 14 \%$ & 15 to $23 \%$ & 24 to $33 \%$ & 34 to $45 \%$ & $\geq 46 \%$ & \\
\hline & 1.0 (Reference) & $1.29(1.03,1.61)$ & $1.49(1.13,1.97)$ & $1.53(1.09,2.14)$ & $1.96(1.09,3.53)$ & $<0.001$ \\
\hline \multicolumn{7}{|c|}{ Odds ratio $(95 \%$ CI $)$ for excess weight (overweight+obese $)^{\text {d,e }}$} \\
\hline \multirow[t]{2}{*}{$\operatorname{Men}(n=14396,42 \%$ excess weight $)$} & $\leq 11 \%$ & 12 to $20 \%$ & 21 to $30 \%$ & 30 to $42 \%$ & $\geq 43 \%$ & \\
\hline & 1.0 (Reference) & $1.14(0.96,1.34)$ & $1.06(0.87,1.29)$ & $1.12(0.87,1.43)$ & $1.17(0.78,1.76)$ & 0.37 \\
\hline \multirow[t]{2}{*}{ Women ( $n=15847,40 \%$ excess weight) } & $\leq 14 \%$ & 15 to $23 \%$ & 24 to $33 \%$ & 34 to $45 \%$ & $\geq 46 \%$ & \\
\hline & 1.0 (Reference) & $1.22(1.03,1.44)$ & $1.34(1.10,1.62)$ & $1.42(1.11,1.80)$ & $1.69(1.12,2.54)$ & $<0.001$ \\
\hline
\end{tabular}

BMI: body mass index

CI: confidence interval

${ }^{a}$ All statistics accounted for sample weights from the national survey

${ }^{\mathrm{b}}$ The quintiles of consumption (\% of total energy) of ultra-processed foods are specific for each subgroup

${ }^{\mathrm{c}} P$ for the interaction term on the linear regression $<0.001$

${ }^{\mathrm{d}}$ Adjusted for age (ln), race (white, African-descendent and other), region (north, northeast, south, southeast, and midwest), urban status (yes/no), smoking (yes/no), physical activity (min/week), quintiles of years of education (age- and sex-specific) per capita household income (ln), consumption of fruits, vegetables and beans (each in \% of total energy intake from non-ultra-processed food) and the interaction between sex and income.

${ }^{\mathrm{e}} \mathrm{BMI}$-for-age $\mathrm{z}$-scores $\geq+2$ for 10 to 19 year-old individuals (de Onis et al., 2007) and BMI $\geq 30 \mathrm{~kg} / \mathrm{m}^{2}$ for $\geq 20$ years old individuals (WHO, 1995). 
${ }^{\mathrm{f}}$ BMI-for-age $\mathrm{z}$-scores $\geq+1$ for 10 to 19 year-old individuals (de Onis et al., 2007) and BMI $\geq 25 \mathrm{~kg} / \mathrm{m}^{2}$ for $\geq 20$ years old individuals (WHO, 1995). 
Supplementary Figure 1. Decision tree for the classification of the food items based on characteristics of food processing and examples.

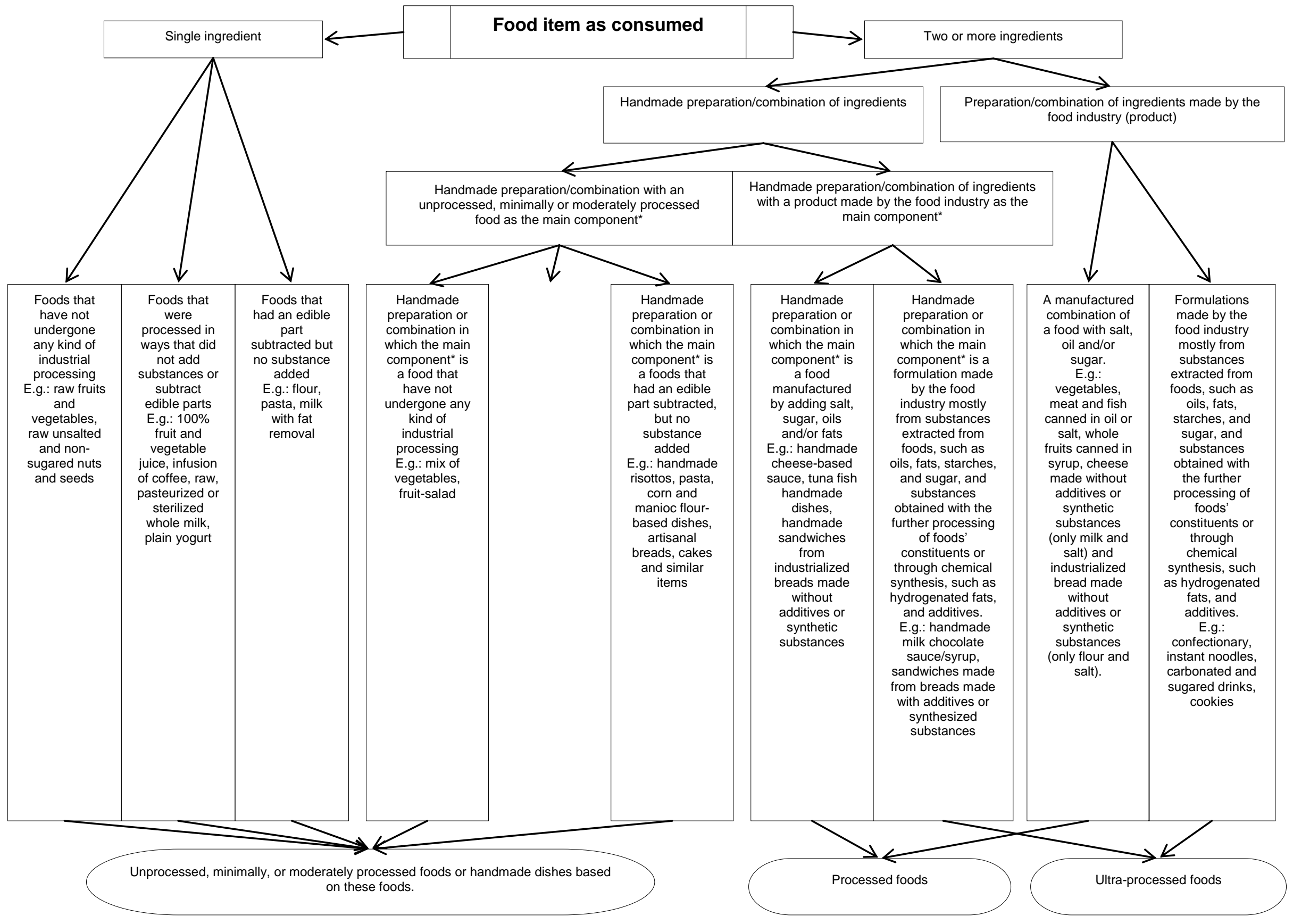


Supplementary Table 1. Characteristics of the food consumption (\% of total energy) of nationally representative adolescents (10 to 19 year-old) and adults $\left(\geq 20\right.$ years old) ${ }^{\text {a }}$. Brazil 2008-2009.

\begin{tabular}{|c|c|c|c|}
\hline Food category $^{\mathbf{b}}$ & $\begin{array}{c}\text { Total } \\
(\mathbf{n}=\mathbf{3 0} 243)\end{array}$ & $\begin{array}{c}\text { Inside home }^{\mathrm{c}} \\
(\mathrm{n}=29984)\end{array}$ & $\begin{array}{l}\text { Outside home }^{\mathrm{d}} \\
\quad(\mathrm{n}=14 \text { 229) }\end{array}$ \\
\hline Unprocessed, minimally and moderately processed foods & 68.6 & 69.4 & 53.2 \\
\hline Rice & 12.5 & 12.6 & 7.7 \\
\hline Beans & 10.2 & 10.2 & 5.9 \\
\hline Red meat & 9.3 & 9.1 & 7.1 \\
\hline Fruits and $100 \%$ fruit juices & 6.9 & 6.7 & 9.9 \\
\hline Corn, oatmeal, wheat (including pasta) & 5.9 & 6 & 4.5 \\
\hline Milk & 5.3 & 6 & 2.5 \\
\hline Poultry & 5.3 & 5.1 & 3.9 \\
\hline Roots and tubers & 3.6 & 3.5 & 2.8 \\
\hline Coffee and tea & 2.9 & 3.1 & 4.2 \\
\hline Fish & 1.7 & 1.7 & 1 \\
\hline Vegetables & 1.6 & 1.6 & 1.9 \\
\hline Eggs & 1.4 & 1.6 & 0.4 \\
\hline Other foods ${ }^{e}$ & 2 & 2.1 & 1.5 \\
\hline Processed foods & 1.8 & 1.9 & 1 \\
\hline Salted meat and fish & 0.7 & 0.7 & 0.4 \\
\hline Cheese & 1 & 1.2 & 0.5 \\
\hline Vegetables in brine or oil and fruits in syrup & 0.1 & 0.1 & 0.1 \\
\hline Ultra-processed foods & 29.6 & 28.7 & 45.8 \\
\hline Industrialized bread & 9.2 & 10.3 & 5.6 \\
\hline Pizzas, hamburgers, sandwiches & 4.7 & 3.7 & 12.8 \\
\hline Cakes, pies and cookies & 3 & 2.8 & 4.6 \\
\hline
\end{tabular}


Sugar-sweetened beverages

Candies, chocolates, gelatin, flan and ice cream

\section{Crackers and chips}

Reconstituted meat products

Flavored or sweetened yogurts or milk beverages

${ }^{a}$ All statistics accounted for sample weights from the national survey

${ }^{b}$ Unprocessed foods have not undergone any kind of industrial processing, minimally processed foods were processed in ways that did not add substances or subtract edible parts, and moderately processed foods had an edible part subtracted, but no substance added. This category includes all handmade dishes made from these foods and culinary ingredients such as fats, oils, salt, and sugar. Processed foods are manufactured by adding salt, sugar, oils or fats to unprocessed, minimally processed or moderately processed foods and ultra-processed foods are formulations mostly or entirely made from substances

extracted from foods, such as oils, fats, starches, sugar, and substances obtained with the further processing of constituents of foods or through chemical synthesis, such as hydrogenated fats, modified starches, and additives used to provide the products with attractive taste, flavor, color, and texture.

${ }^{\mathrm{c}}$ Consumption of food groups (\% of total energy intake consumed inside the home) of the 29984 individuals that reported consumption inside home.

${ }^{\mathrm{d}}$ Consumption of food groups (\% of total energy intake consumed inside the home) of the 14229 individuals that reported consumption inside home. ${ }^{\mathrm{e}} \mathrm{Nuts}$ and seed, lentil, peas and soy, plain yogurt, shellfish and other mixed dishes

${ }^{\mathrm{f}}$ Margarine, ready-to-eat sauces and breakfast cereals 
Supplementary Table 2. Characteristics of the 30243 individuals aged $\geq 10$ years old across quintiles of consumption of ultra-processed foods (\% of total energy) ${ }^{\mathrm{a}}$. Brazil 2008-2009.

\begin{tabular}{|c|c|c|c|c|c|}
\hline \multirow[b]{4}{*}{ Total energy intake in kcal, mean (SD) } & \multicolumn{5}{|c|}{ Quintiles of ultra-processed foods (\% of total energy) } \\
\hline & 1 & 2 & 3 & 4 & $5^{b}$ \\
\hline & $(\leq 13 \%)$ & (14 to $22 \%)$ & $(23$ to $31 \%)$ & $(32$ to $43 \%)$ & $(\geq 44 \%)$ \\
\hline & $1784(770)$ & $1849(701)$ & $1884(697)$ & $1964(726)$ & $\begin{array}{l}2060 \\
(823)\end{array}$ \\
\hline$\%$ of food consumption outside home, mean (SD) & $12(23)$ & $17(25)$ & $19(25)$ & $23(26)$ & $26(27)$ \\
\hline \multicolumn{6}{|l|}{ Age } \\
\hline 10 to $19 \mathrm{y}, \%$ & 16 & 19 & 26 & 35 & 38 \\
\hline 20 to $39 \mathrm{y}, \%$ & 38 & 41 & 43 & 44 & 41 \\
\hline 40 to $59 \mathrm{y}, \%$ & 32 & 30 & 27 & 24 & 17 \\
\hline 60 y or more, $\%$ & 14 & 11 & 8 & 6 & 4 \\
\hline \multicolumn{6}{|l|}{ Sex } \\
\hline Men, \% & 59 & 50 & 49 & 47 & 45 \\
\hline Women, \% & 41 & 50 & 51 & 53 & 55 \\
\hline \multicolumn{6}{|l|}{ Race } \\
\hline White, \% & 34 & 43 & 49 & 54 & 57 \\
\hline African-descendent, $\%$ & 64 & 56 & 50 & 45 & 41 \\
\hline Other, $\%$ & 2 & 1 & 1 & 1 & 1 \\
\hline \multicolumn{6}{|l|}{ Urbanity } \\
\hline Rural, \% & 37 & 20 & 12 & 9 & 6 \\
\hline Urban, $\%$ & 63 & 80 & 88 & 91 & 94 \\
\hline \multicolumn{6}{|l|}{ Smoking status } \\
\hline Current smokers ${ }^{\mathrm{c}}, \%$ & 12 & 8 & 7 & 8 & 5 \\
\hline \multicolumn{6}{|c|}{ Leisure-time and transportation physical activity in min/week ${ }^{\mathrm{d}}$} \\
\hline$<150, \%$ & 45 & 40 & 32 & 27 & 20 \\
\hline
\end{tabular}


$\geq 150, \%$

Years of education

$\leq 4, \%$

5 to $8, \%$

9 to $12, \%$

$>12, \%$

Annual household income per person ${ }^{\mathrm{e}}$ in US\$, \%

$\leq 2200$

2201 to 4400

$>4400$

${ }^{a}$ All statistics accounted for sample weights from the national survey

${ }^{\mathrm{b}}$ All the characteristics were significantly associated with the consumption of ultra-processed foods $(P<0.001)$

'The number of smokers was estimated based on the number of individuals that purchased cigarettes (budget survey data). Former smoker data not available

${ }^{\mathrm{d}}$ Physical activity was estimated with a linear regression model fitted with original data from previous Brazilian population-based surveys with age, sex, race, years of education and smoking status as the predictors.

${ }^{\mathrm{e}}$ Annual household income per person was calculated using a purchasing power parity basis (PPP 2009: US\$ $1.00=$ RS 1.63), multiplying by 12 months, and dividing by the number of residents in the household.

$37 \quad 27$

